\title{
Dielectric properties of CaCu3- xMgxTi4O12 (x=0.20 and 0.50) material synthesized by the semi-wet route for energy storage capacitor
}

Laxman Singh, U. S. Rai, N. B. Singh, Y. Lee, D. K. Mahato, et al.

Laxman Singh, U. S. Rai, N. B. Singh, Y. Lee, D. K. Mahato, Divyanshu Bhardwaj, K. D. Mandal, "Dielectric properties of CaCu3-xMgxTi4O12 ( $x=0.20$ and 0.50) material synthesized by the semi-wet route for energy storage capacitor," Proc. SPIE 11020, Smart Biomedical and Physiological Sensor Technology XV, 1102002 (2 May 2019); doi: 10.1117/12.2515634

Event: SPIE Defense + Commercial Sensing, 2019, Baltimore, Maryland, United States 


\title{
Dielectric properties of $\mathrm{CaCu}_{3-\mathrm{x}} \mathrm{Mg}_{\mathrm{x}} \mathrm{Ti}_{4} \mathrm{O}_{12}(\mathrm{x}=0.20 \&$ 0.50) material synthesized by the semi-wet route for energy storage capacitor
}

Laxman Singh $^{\mathrm{a}^{*}}$, U. S. Rai ${ }^{\mathrm{b}}$, N.B. Singh ${ }^{\mathrm{c}}$, Y. Lee ${ }^{\mathrm{d}}$, D. K. Mahato ${ }^{\mathrm{e}}$, Divyanshu Bhardwaj ${ }^{\mathrm{f}}$, and K. D. Mandal $\mathrm{g}^{* *}$

aDepartment of Chemistry, RRS College, Patliputra University, Patna-80330, Bihar.

${ }^{b}$ Department of Chemistry, Centre of Advanced Study, Institute of Science, Banaras Hindu University, Varanasi - 221005, U.P. (India)

'Department of Chemistry and Biochemistry, University of Maryland Baltimore County, Baltimore, MD 21250, USA

${ }^{\text {d} D e p a r t m e n t ~ o f ~ C h e m i s t r y, ~ U n i v e r s i t y ~ o f ~ U l s a n, ~} 93$ Daehak-ro Nam-gu, Ulsan 680-749, Republic of Korea

eDepartment of Physics, National Institute of Technology, Patna-800005, Bihar

fDepartment of Computer Science and Engineering, SRM Institute of Science and Technology, Ramapuram, Chennai-600089, India

gDepartment of Chemistry, Indian Institute of Technology, Banaras Hindu University, Varanasi 221005, U.P. (India)

\begin{abstract}
Dielectric properties of high percentage $\mathrm{Mg}$ doped $\mathrm{CaCu}_{3} \mathrm{Ti}_{4} \mathrm{O}_{12}, \mathrm{CaCu}_{3-\mathrm{x}} \mathrm{Mg}_{\mathrm{x}} \mathrm{Ti}_{4} \mathrm{O}_{12}(\mathrm{x}=0.20 \& 0.50)$ ceramics carried out. They were synthesized by the semi-wet route using a solution based citrate-nitrate method along with inexpensive solid $\mathrm{TiO}_{2}$ powder. X-ray diffraction analysis reveals that the ceramics form single phase when sintered at $950{ }^{\circ} \mathrm{C}$ for $12 \mathrm{~h}$. SEM analyses show the smooth surfaces of grains with a spherical appearance. The grains of CCMTO2 and CCMTO5 ceramics were found to be in the size range of 1-5 $\mu \mathrm{m}$ and 1-3 $\mu \mathrm{m}$, respectively. Dielectric studies show that the CCMTO2 ceramic has higher value of dielectric constant and lower dielectric loss in comparison to that of CCMTO5.
\end{abstract}

Keywords: Ceramics; Oxides; Chemical synthesis; Calcium copper titanate;

Corresponding author:

laxmanresearcher84@gmail.com*,kdmandal.apc@itbhu.ac.in**

\section{Introduction}

It is well known that $\mathrm{CaCu}_{3} \mathrm{Ti}_{4} \mathrm{O}_{12}$ (CCTO) perovskite oxide possess high dielectric constant with good thermal stability [1]. Several other ceramic materials such as hexagonal $\mathrm{BaTiO}_{3}$ and $(\mathrm{Li}, \mathrm{Ti})$ doped $\mathrm{NiO}$ etc. possessing colossal high dielectric constant are also reported [2,3]. CCTO with very high dielectric constant in the range, $10^{4}-10^{5}$, at radio frequency and below near room temperature shows a good temperature stability over a wide temperature range from 100-600 K [4,

Smart Biomedical and Physiological Sensor Technology XV, edited by Brian M. Cullum,

Douglas Kiehl, Eric S. McLamore, Proc. of SPIE Vol. 11020, 1102002 · @ 2019

SPIE · CCC code: 0277-786X/19/\$18 - doi: 10.1117/12.2515634 
5]. Also, its cubic structure $(\mathrm{a}=7.391 \AA)$ remains unchanged, suggesting thereby that no structural phase transition occurs. There are several explanations for the origin of colossal dielectric property of CCTO but the intrinsic or extrinsic effects are the most important among them. While the intrinsic model is attributed to local dipole moments related to off-canter displacement of $\mathrm{Ti}$ ions [6], the evidences of the extrinsic model come from impedance spectroscopy measurements [7], first-principle calculations [8], infrared measurements [9], in-homogeneity morphology analysis [10], the electrode polarization effect [11], and the heat treatment effects [12-14]. However, the internal barrier layer capacitor (IBLC) model representing semiconducting grains and insulating grain boundaries [15] has been widely accepted for the abnormal dielectric response in CCTO. The origins of semi-conductive grains and highly resistive grain boundary were not established, but two models, oxygen loss and oxygen stoichiometric have been proposed. The dielectric response of this material was found to be very sensitive to the microstructure (such as grain size) and processing condition [16] as well as doping $[17,18]$. There are many examples for doping effects of different ions in the literature such as substitution of Mn, $\mathrm{Zn}$ and $\mathrm{Mg}$ for $\mathrm{Cu}$ [19-24], $\mathrm{La}$ for $\mathrm{Ca}$ [25, 26], $\mathrm{W}$ for Ti site [27]. In the present paper, the high percentage of $\mathrm{Mg}$ substituted $\mathrm{CCTO}, \mathrm{CaCu}_{3}-\mathrm{Mg}_{\mathrm{x}} \mathrm{Ti}_{4} \mathrm{O}_{12}(\mathrm{x}=0.20 \& \mathrm{x}=0.50)$ ceramics were synthesized by the semi-wet route. The resulting ceramic shows higher $\mathrm{Mg}^{2+}$ solubility in $\mathrm{CaCu}_{3-\mathrm{x}} \mathrm{Mg}_{\mathrm{x}} \mathrm{Ti}_{4} \mathrm{O}_{12}$ system $\mathrm{x} \leq 0.50$ due to diffusion of metal cations at atomic scale than other solid state ceramic routes reported earlier [28-29].

\section{Experimental}

Analytical grade chemicals $\mathrm{Ca}\left(\mathrm{NO}_{3}\right)_{2} .4 \mathrm{H}_{2} \mathrm{O}, \mathrm{Cu}\left(\mathrm{NO}_{3}\right)_{2} .3 \mathrm{H}_{2} \mathrm{O}, \mathrm{Mg}\left(\mathrm{NO}_{3}\right)_{2} .2 \mathrm{H}_{2} \mathrm{O}, \mathrm{TiO}_{2}$ and citric acid, having purity of $\sim 99.5 \%$ were used as starting materials for synthesizing $\mathrm{CaCu}_{3-\mathrm{x}} \mathrm{Mg}_{\mathrm{x}} \mathrm{Ti}_{4} \mathrm{O}_{12}$ (where $\mathrm{x}=0.20$ and 0.50 ) abbreviated as CCMTO2 and CCMTO5, respectively. Aqueous solutions of calcium nitrate, copper nitrate and magnesium nitrate, in stoichiometric amount, were mixed in a beaker and calculated amounts of solid $\mathrm{TiO}_{2}$ and aqueous citric acid were added to the mixture. The heterogeneous solution was heated on a hot plate using a magnetic stirrer at $70-80{ }^{\circ} \mathrm{C}$ to evaporate water and dried at $100-120^{\circ} \mathrm{C}$ in hot air oven for $12 \mathrm{~h}$ to yield a blue gel. The gel was calcined in air at $800{ }^{\circ} \mathrm{C}$ for $6 \mathrm{~h}$ in a muffle furnace. The resultant mixtures were converted into fine powder using a pestle and mortar and then it was used to make cylindrical pellets using hydraulic press. The pellets were sintered at $950^{\circ} \mathrm{C}$ for $12 \mathrm{~h}$ in air. The crystalline phases of the sintered ceramics were identified using an X-ray Diffractometer (Rich-Siefert, ID-3000) employing Cu-K $\mathrm{K}_{\alpha}$ radiation. The particle size was examined using high resolution transmission electron microscope (FEI Technai F30). The microstructures of the fractured surface were examined using a Scanning Electron Microscope (JEOL JSM5410) attached with EDX analyser. The dielectric and impedance measurements were made using pellets, both surfaces of which were polished and coated with silver paint, by the impedance analyzer (HP 4294 A).

\section{Results and discussion}

XRD patterns of CCMTO2 and CCMTO5 electro-ceramics sintered at $950{ }^{\circ} \mathrm{C}$ for $12 \mathrm{~h}$ are shown in Fig.1. X-Ray data were indexed on the basis of a cubic unit cell similar to un-doped CCTO (JCPDS 75-2188), which confirm the formation of its single phase. The lattice parameters determined by the least square refinement method using most intense (220) diffraction peak, are 7.394 and $7.400 \AA$, respectively for CCMTO2 \& CCMTO5. There is no evidence of the presence 
of secondary phase. XRD patterns show the presence of split peaks for the reflections at 400, 422 and 440 . This may be due to presence of $\mathrm{Cu}-\mathrm{K} \alpha_{2}$ along with $\mathrm{Cu}-\mathrm{K} \alpha_{1}$ in the $\mathrm{X}$-ray radiations used for the diffraction studies.

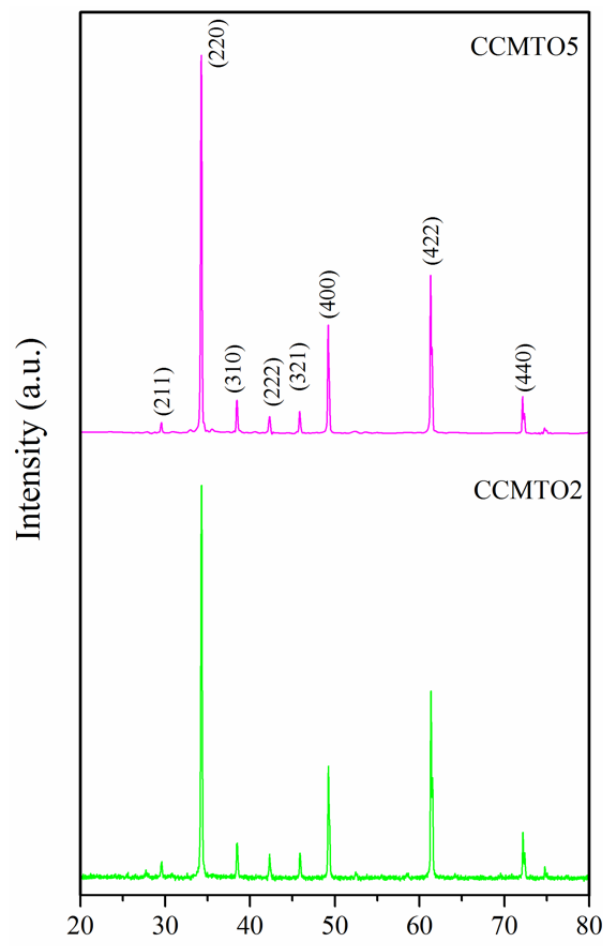

Fig. $1 \mathrm{X}$-ray powder diffraction patterns of $\mathrm{CaCu}_{3-\mathrm{x}} \mathrm{Mg}_{\mathrm{x}} \mathrm{Ti}_{4} \mathrm{O}_{12}(\mathrm{x}=0.20 \& 0.50)$ sintered at $950{ }^{\circ} \mathrm{C}$ for $12 \mathrm{~h}$.

Fig. $2(a, b)$ shows a representative bright field TEM image and corresponding selected area electron diffraction patterns (SAED) of the CCMTO2 ceramic. The particle size was found to be in the range of $70 \pm 12 \mathrm{~nm}$. In addition, the SAED pattern 2 (b) confirmed the presence of single-phase polycrystalline material. The diffraction patterns have been indexed on the basis of cubic crystal structure with (220) plane. The additional spots observed in the SAED patterns are from adjacent grains and sub-grains due to their orientation in diffraction directions.
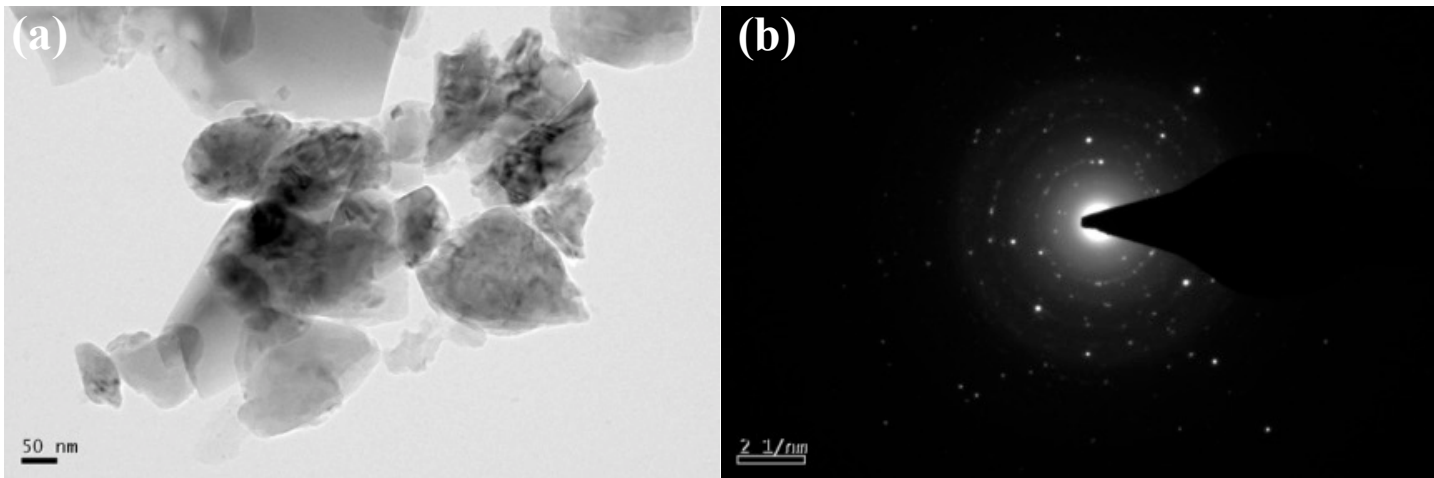

Fig. 2 (a) Bright field TEM images (b) Corresponding selected area diffraction pattern (SAED) of CCMTO2 sintered at $950^{\circ} \mathrm{C}$ for $12 \mathrm{~h}$. 
The microstructures of the CCMTO2 and CCMTO5 electro-ceramics are shown in Fig. 3. The grain size range of CCMTO2 and CCMTO5 are $1-5 \mu \mathrm{m}$ and $1-3 \mu \mathrm{m}$, respectively. The CCMTO ceramics with $\mathrm{x}=0.20$ and 0.50 exhibit dense microstructure with abnormally large grains with very small grains segregating at grain boundaries. The grains of both ceramics have smooth surfaces associated with a spherical appearance. The CCMTO2 displayed the significant feature that the grains are surrounded by secondary phase of $\mathrm{CuO}$ along with some amount of $\mathrm{Mg}$ and $\mathrm{Ti}$ present at grain-boundaries. The presence of $\mathrm{CuO}$ rich phase formation of insulating grain boundary layers can be regarded as a predominant reason for the high dielectric permittivity.

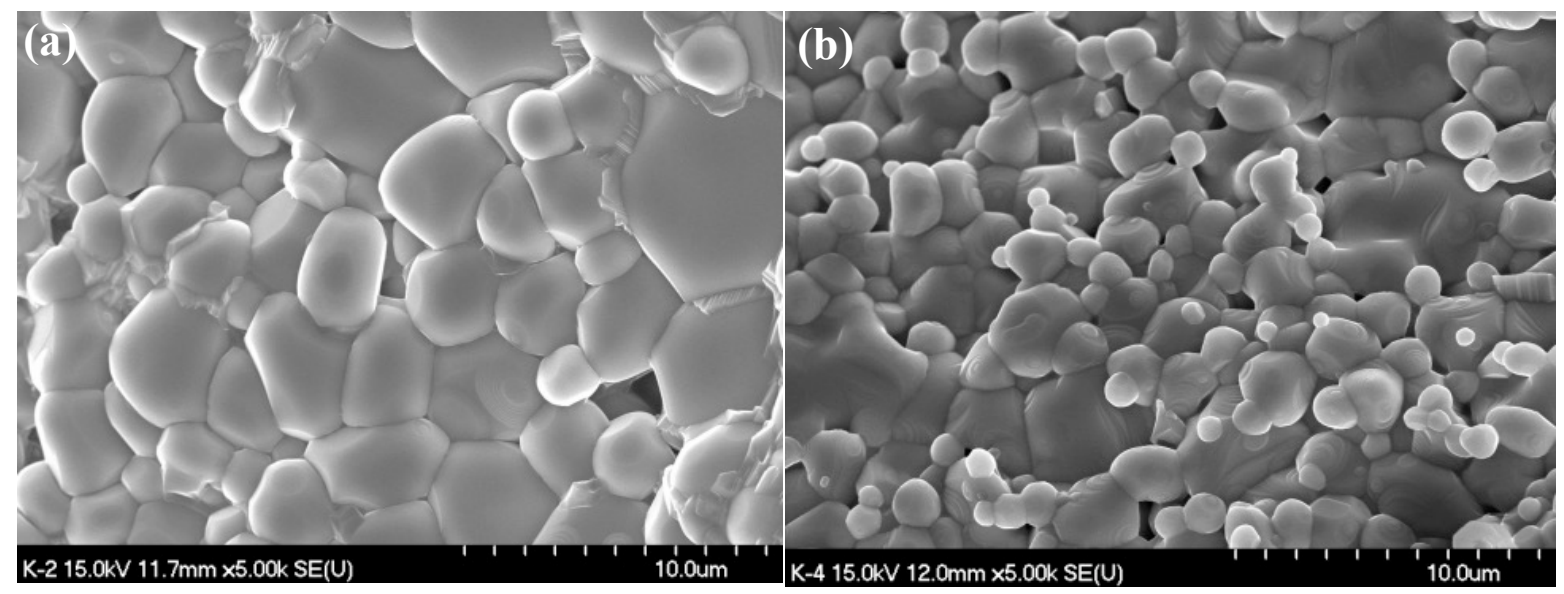

Fig. 3 SEM micrographs of (a) CCMTO2 and (b) CCMTO5 sintered at $950^{\circ} \mathrm{C}$ for $12 \mathrm{~h}$.

The atomic percentage data of grains and grain-boundaries for CCMTO2 composition were also obtained by Energy dispersive X-ray (EDX) analysis. The atomic percentage of elements $\mathrm{Mg}, \mathrm{Ca}, \mathrm{Ti}$ and $\mathrm{Cu}$, at grains 2.34, 12.41, 48.83 and 36.43 and at grain-boundaries 1.32, 6.93, 24.90 and 66.86, respectively. The EDX data of grain-boundary shows the copper rich phase with $\mathrm{Mg} \& \mathrm{Ti}$ content grain-boundary. The presence of rich $\mathrm{CuO}$ phase at the grain-boundaries suggests that the grain boundary effects are responsible for the enhanced dielectric permittivity [30, 31].

Plots of dielectric constant $\left(\varepsilon_{r}\right)$ and dielectric loss $(\tan \delta)$ as a function of temperature of CCMTO2 and CCMTO5 ceramics for few selected frequencies are shown in Figs. 4(a, b) and 5(a, b), respectively. It is apparent that both the ceramics exhibit high dielectric constant. The values of dielectric constant of these ceramics are higher than those of un-doped CCTO reported earlier [32]. The values of dielectric constant of CCMTO2 and CCMTO5 were found to be $\varepsilon_{r} \sim 32.5 \times 10^{3}$ and $9.8 \times 10^{3}$ at $1 \mathrm{kHz}$ and at $453 \mathrm{~K}$, respectively and decrease in the case CCMTO5 with very high percentage $(\mathrm{x}=0.50)$ magnesium concentration. The dielectric constant of CCMTO5 at $10 \mathrm{kHz}$ remains almost constant in the temperature range 300- $500 \mathrm{~K}$ while in the case of CCMTO2 it increases with increasing temperature beyond $400 \mathrm{~K}$. The dielectric loss (tan

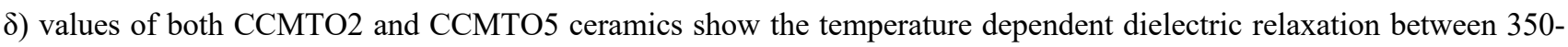
$500 \mathrm{~K}$. 

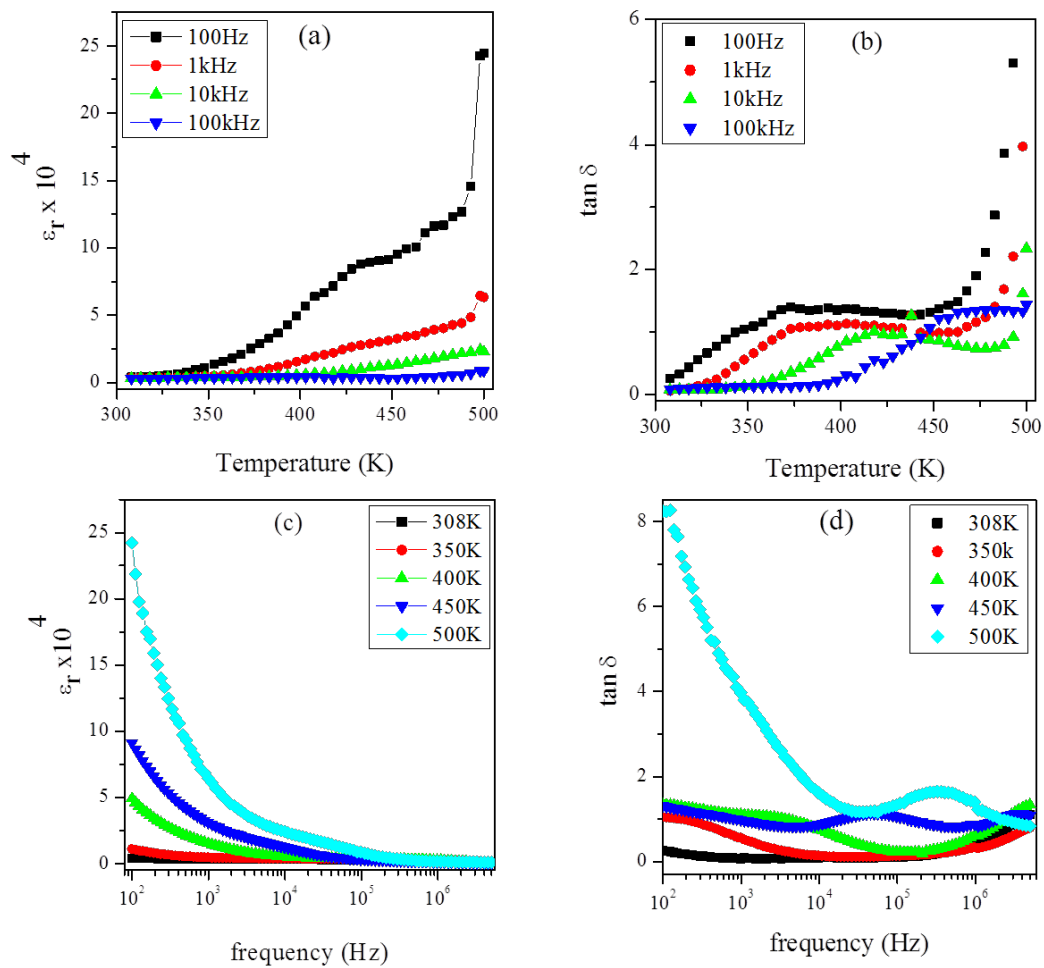

Fig. 4 Plots of (a) dielectric constant $\left(\varepsilon_{\mathrm{r}}\right)$ vs T (b) dielectric loss ( $\left.\tan \delta\right)$ vs T (c) dielectric constant $\left(\varepsilon_{\mathrm{r}}\right)$ vs $f(\mathrm{~d}) \operatorname{dielectric} \operatorname{loss}(\tan \delta)$ vs $f$ for CCMTO2

Plots of dielectric constant $\left(\varepsilon_{r}\right)$ and dielectric loss $(\tan \delta)$ as a function of frequency for CCMTO2 and CCMTO5 ceramics for few selected temperatures are shown in Fig. 4(c, d) and 5(c, d). The dielectric constant values for CCMTO2 \& CCMTO5 ceramics decrease rapidly $\left(10^{2}-10^{3} \mathrm{~Hz}\right)$ and then remain nearly constant between $10 \mathrm{kHz}-5 \mathrm{MHz}$. It is also noted that $\varepsilon_{r}$ values decrease with increasing frequency. The values of $\tan \delta$ for the CCMTO2 and CCMTO5 at $453 \mathrm{~K}$ are 0.98 and 3.3, respectively at $1 \mathrm{kHz}$. It is also observed from the figure that dielectric loss for both the ceramics show dielectric relaxation behaviour in low frequency range region (below than $10^{3} \mathrm{~Hz}$ ) as well as in high frequency ranges (above $10^{5} \mathrm{~Hz}$ ). The low frequency relaxation may be due to space charge polarization which arises when two phases of grain-grain boundaries of different electrical conductivity are in contact $[33,34]$. The high frequency relaxation above $10^{5}$ $\mathrm{Hz}$ in these ceramics is probably due to the resonance effect arising from the stray inductance of the contacts [35]. 

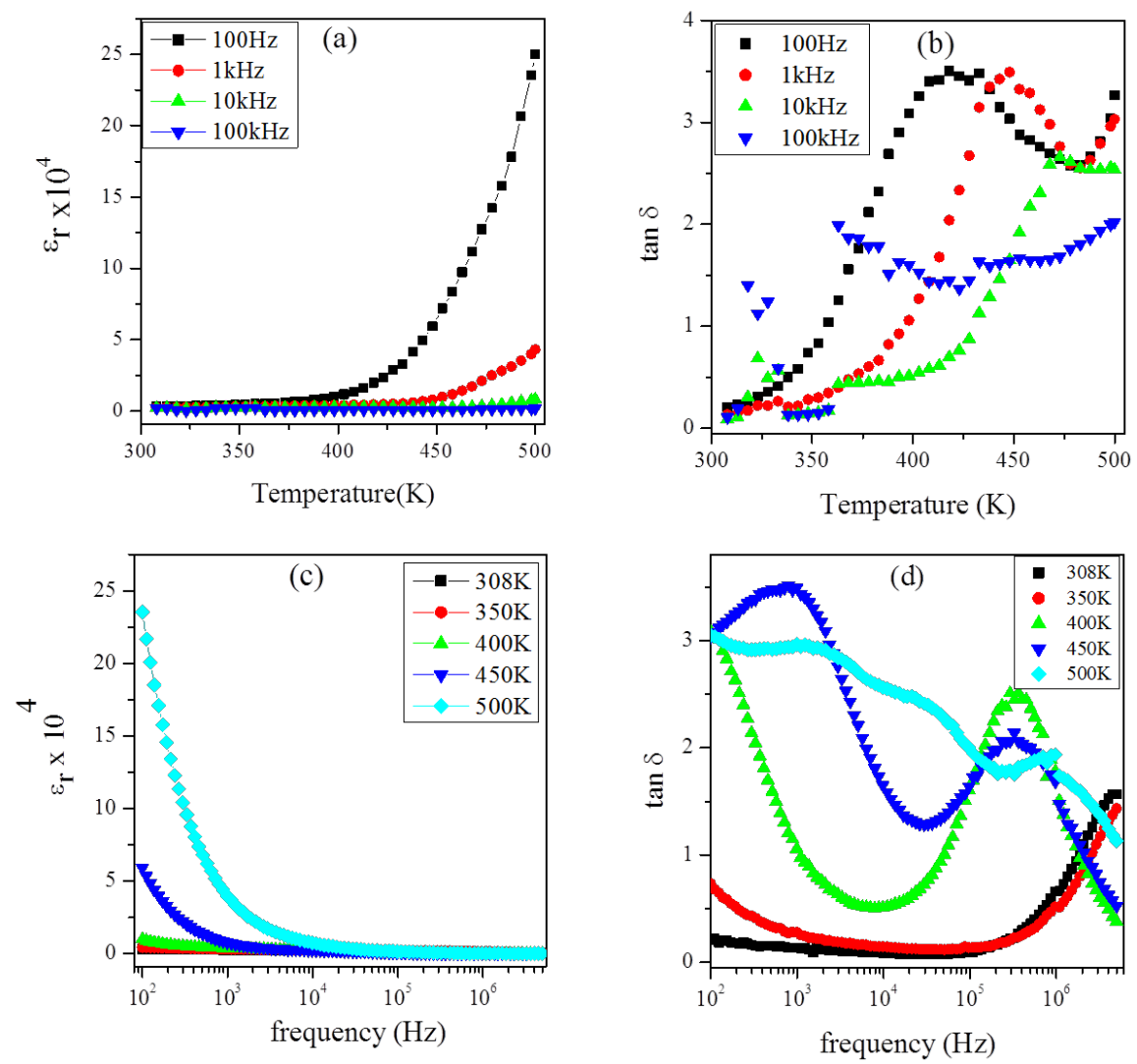

Fig. 5 Plots of (a) dielectric constant $\left(\varepsilon_{\mathrm{r}}\right)$ vs T (b) dielectric loss ( $\tan \delta$ ) vs T (c) dielectric constant ( $\left.\varepsilon_{\mathrm{r}}\right)$ vs $f(\mathrm{~d}) \operatorname{dielectric}$ loss (tan $\left.\delta\right)$ vs $f$ for CCMTO5

The increase in dielectric constant by the substitution of $\mathrm{Mg}^{+2}$ ions can be explained by the following mechanism: these ceramic materials are expected to loss of traces of oxygen during their sintering at high temperature in accordance with reaction given below [36];

$$
O_{o} \leftrightarrow \frac{1}{2} O_{2}+V_{o}^{\bullet \bullet}+2 e^{\prime}
$$

where all the species are written in accordance with Kroger-Vink Notation of defects [37, 38]. Electrons released in the above reaction may be captured by $\mathrm{Cu}^{2+}$ or $\mathrm{Ti}^{4+}$ to produce $\mathrm{Cu}^{+}$or $\mathrm{Ti}^{3+}$, respectively, as given below:

$$
\begin{aligned}
2 \mathrm{Cu}^{2+}+2 \mathrm{e}^{-} & \rightarrow 2 \mathrm{Cu}^{+}, \\
2 \mathrm{Ti}^{4+}+2 \mathrm{e}^{-} & \rightarrow 2 \mathrm{Ti}^{3+},
\end{aligned}
$$

The presence of $\mathrm{Cu}^{+}$and $\mathrm{Ti}^{3+}$ in CCMTO ceramic was also reported by L. Ni et al. On increasing the Mg doping in CCTO, the ratio of $\mathrm{Cu}^{+} / \mathrm{Cu}^{++}$and $\mathrm{Ti}^{3+} / \mathrm{Ti}^{4+}$ also increases and this was confirmed by X-ray photoelectron spectroscopy (XPS) studies $[39,40]$. The formation of $\mathrm{Cu}^{+}$and $V_{o}^{\bullet \bullet}$ may be suggested in accordance with the following equation (7):

$$
3 \mathrm{Cu}_{\mathrm{cu}}^{x}+\mathrm{O}_{\mathrm{O}}^{x} \stackrel{M g O}{\longrightarrow} \mathrm{Mg}_{\mathrm{Cu}}^{x}+2 \mathrm{Cu}_{\mathrm{cu}}^{\prime}+V_{o}^{\bullet \bullet}+\mathrm{CuO}+1 / 2 \mathrm{O}_{2}
$$


On substitution of one $\mathrm{Mg}^{2+}$ cation at $\mathrm{Cu}^{2+}$ site converted two $\mathrm{Cu}^{2+}$ in to two $\mathrm{Cu}^{+}$ions at its lattice sites. In this process replaced $\mathrm{Cu}^{2+}$ combine with vacated $\mathrm{O}^{2-}$ ions and form $\mathrm{CuO}$ which segregated at grain boundary. The presence of $\mathrm{CuO}$ phase at grain-boundary was also supported by SEM and EDX analyses. These results conclude that on Mg doping in CCTO, oxygen vacancies and ratio of $\mathrm{Cu}^{+} / \mathrm{Cu}^{++}$and $\mathrm{Ti}^{3+} / \mathrm{Ti}^{4+}$ ions increase. Therefore, the above results are responsible for high dielectric constant in Mg doped CCMTO2 and CCMTO5.

\section{Conclusions}

We have successfully synthesized high percentage $\mathrm{Mg}$ substituted CCTO, $\mathrm{CaCu}_{3}-\mathrm{x} \mathrm{Mg}_{\mathrm{x}} \mathrm{Ti}_{4} \mathrm{O}_{12}(\mathrm{x}=0.20 \& 0.50)$ ceramics at relatively low temperatures and short heat treatment duration. XRD patterns indicate that the ceramics form single phase. The SEM morphology shows the grains have smooth surfaces associated with a spherical appearance. The

dielectric measurements show that $\mathrm{CaCu}_{3-\mathrm{x}} \mathrm{Mg}_{\mathrm{x}} \mathrm{Ti}_{4} \mathrm{O}_{12}(\mathrm{x}=0.20 \& 0.50)$ ceramics exhibit higher values of dielectric constant $\varepsilon_{r} \leq 10^{3}$.

\section{Acknowledgement}

Authors are grateful Head, Department of Ceramic Engineering, IIT, BHU, for providing XRD facility. We are also thankful to Dr. R. N. Rai, Department of Chemistry, BHU, for extending Impedance Analyzer facility.

\section{References}

[1] Homes, C. C., Vogt, T., Shapiro, S. M., Wakimoto, S., Ramirez, A. P. Sci. 293, 673-676 (2001).

[2] Yu, J., Paradis, P. F., Ishikawa, T., Yoda, S. Appl. Phys. Lett. 85, 2899 (2004)

[3] Wu, J., Nan, C. W., Lin, Y., Deng,Y. Phys. Rev. Lett. 89, 217601 (2002)

[4] Subramanian, M. A., Li, D., Duan, N., Reisner, B. A., Sleight, A. W. J. Solid-State Chem. 151, 323-325 (2000).

[5] Singh, L., Kim, I. W., Woo, W. S., Sin, B. C., Lee, H., Lee, Y. Solid State Sci. 43, 35-45 (2015).

[6] Singh, L., Rai, U. S., Mandal, K. D., Singh, N. B. Prog. in Crys. Growth and Charac of Mater. 60, 15-62 (2014).

[7] Sinclair, D. C., Adams, T. B., Morrison, F. D., West, A. R. Appl. Phys. Lett. 80, 2153-2155 (2002).

[8] He, L. X., Neaton, J. B., Cohen, M. H., Vanderbbilt, D., Homes, C. C. Phys. Rev. B 65, 214112 (2002).

[9] Homes, C. C., Vogt, T., Shapiro, S. M., Wakimoto, S., Subramanian, M. A., Ramirez, A. P., Phys. Rev. B 67, 092106 (2003).

[10] Cohen, M. H., Neaton, J. B., He, L. X., Vanderbbilt, D. J. Appl. Phys. 94, 3299(2003).

[11] Lunkenheimer, P., Bobnar, V., Pronin, A. V., Ritus, A. I., Volkov, A. A., Loidl A. Phys. Rev. B 66, 052105 (2002).

[12] Fang, L., Shen, M. R., Cao, W. W. J. Appl. Phys. 95, 6483 (2004).

[13] Tselev, A., Brooks, C. M., Anlage, S. M., Zheng, H., Salamanca, L. R., R., Ramesh, Subramanian, M. A. Phys. Rev. B 70, 144101(2004).

[14] Rai, U. S., Singh, L., Mandal, K. D., Singh, N. B. Nanosci. Technol. 1, 1-17 (2014). 
[15] Adams, T. B., Sinclair, D. C., West, A. R. Adv. Mater. 14, 1321-1323 (2002).

[16] Bender, B. A., Pan, M. J. Mater. Sci. Eng. B 117, 339-347 (2005).

[17] Chiodelli, G., Massarotti, V., Capsoni, D., Bini, M., Azzoni, C. B., Mozzati, M. C., Lupotto, P. Solid-State Commun. 132, 241-246 (2004).

[18] Singh, L., Rai, U. S., Rai, A. K., Mandal, K. D. J of Adv Ceram. 2, 119-127 (2013).

[19] Kobayashi, W., Terasaki, I. Phys. B 771, 329 (2003)

[20] Li, M., Feteira, A., Sinclair, D. C., West, A. R. Appl. Phys. Lett. 88, 232903 (2006).

[21] Hutagalung, S. D., Ooi, L. Y., Ahmad, Z. A. J. of Alloy. Compd. 476, 477-481 (2009).

[22] Xu, D., Zhang, C., Cheng, X. N., Fan, Y., Yang, T., Yuan, H. M. Adv. Mater. Res. 197, 302-305 (2001).

[23] Li, M., Chen, X. L., Zhang, D. F., Wang, W. Y., Wang, W. J. Sens. and Actuat. B: Chem. 147, 447-452 (2010).

[24] Ni, L., Chen, X. M. Solid State Comm. 149, 379-383 (2009).

[25] Feng, L., Tang, X., Yan, Y., Chen, X., Jiao, Z., Cao, G. Phys. Status Solidi A 203, R22-R24 (2006).

[26] Prakash, B. S., Varma, K. B. R. J. Mater. Sci.: Mater. Electron. 17, 899-907 (2006).

[27] Singh, L., Sin, B. C., Kim, I. W., Mandal, K. D., Chung, H., Lee, Y. J. Am. Ceram. Soc. 99, 27-34 (2016).

[28] Li, M., Cai, G., Zhang, D. F., Wang, W. Y., Wang, W. J., Chen, X. L. J. Appl. Phys. 104 (2008) 074107

[29] Wang, L., Shenyu, Q., Nan, C., Guoping, D. J. Mater. Sci. Tech. 26, 682-686 (2010).

[30] Kim, D. W., Kim, T. G., Hong, F. S. Mater. Res. Bull. 34, 771-781 (1999).

[31] Huang, C. L., Chen, Y. C. Mater. Res. Bull. 37, 563-574 (2002).

[32] Singh, L., Rai, U.S., Mandal, K.D. Adv. in Appl. Ceram. 111, 374-380 (2012).

[33] Zhang, J. L., Zheng, P., Wang, C. L., Zhao, M. L., Wang, J. F. Appl. Phys. Lett. 87, 142901 (2005).

[34] Singh, L., Yadava, S. S., Woo, W. S., Rai, U.S., Mandal, K. D., Sin, B.C., Lee, Y. Appl. Spectrosc. Rev. 51, $735-$ 752 (2016).

[35] Joshi, P. C., Desu, S. B. J. Appl. Phys. 80, 2349 (1996).

[36] Parkash, O., Kumar, D., Goyal, A., Agrawal, A., Mukherjee, A., Singh, S., Singh, P. J. Phys. D: Appl. Phys. 41, 035401 (2008).

[37] Burn, I., Neirman, S. J. Mater. Sci. 17, 3510-3524(1982).

[38] Neirman, S., Burn, I. J. Mater. Sci. 17, 737-744 (1982).

[39] Li, M., Cai, Gemei, Zhang, D. F., Wang, W. Y., Wang, W. J., Chen, X. L. J. Appl. Phys. PHYSICS 104, 074107 (2008).

[40] Ni, L., Chen, X. M. Appl. Phys. Lett. 91, 122905 (2007). 